\title{
PERAN PEMERINTAH DAERAH DALAM MELESTARIKAN PEMBERIAN GELAR ADAT DI BOLAANG MONGONDOW RAYA
}

\author{
Gusniarjo Mokodompit, Nur Mohamad Kasim \\ Universitas Negeri Gorontalo \\ Jl. Jenderal Sudirman No.6, Dulalowo Tim., Kota Tengah, Kota Gorontalo, Gorontalo \\ 96128 \\ e-mail: nurkasim76@yahoo.co.id
}

\begin{abstract}
Abstrak: Sejarah masuknya aturan hukum dari Belanda pada masa penjajahan menjadikan Indonesia sebagai bangsa yang wajib menggunakan hukum yang dibawa oleh bangsa penjajah tersebut. Diwajibkannya menggunakan aturan hukum dari luar, berhasil mengeyampingkan aturan hukum adat yang memang sudah menjadi ciri khas setiap daerah adat di Indonesia. Hal ini kemudian menjadikan hukum adat itu lemah. Lemahnya hukum adat berdampak pada tidak dijiwainya lagi hukum adat sebagai aturan yang sesuai dengan tatacara berkehidupan masyarakat Indonesia, hal ini terjadi pada Prosesi Pemberian Gelar Adat yang ada di Bolaang Mongondow Raya. Prosesi adat tertinggi yang harusnya sangtalah sakral tidak lagi menjadi suatu hal yang disakralkan dan jauh dari perhatian pemerintah. Oleh karena itu pembentukan Lembaga adat oleh pemerintah menjadi sesuatu yang urgen untuk menyelamatkan semua prosesi adat termasuk Pemberian Gelar Adat.
\end{abstract}

Kata Kunci : Hukum Adat, Gelar Adat, Lembaga Adat.

\begin{abstract}
The history of the entry of the rule of law from the Dutch in the colonial period made Indonesia as a nation that must use the law brought by the colonial nation. Required to use the rule of law from the outside, managed to override the rules of customary law that is already a hallmark of each customary area in Indonesia. This then makes the customary law weak. The weakness of customary law has an impact on the unadulteration of customary law as a rule that is in accordance with the Indonesian people's living order, this happens in the procession of giving traditional titles in Bolaang Mongondow Raya. The highest customary procession that should be sacred is no longer a sacred thing and far from the attention of the government. Therefore, the establishment of customary institutions by the government becomes something urgent to save all custom processions including the Provision of Adat Title.
\end{abstract}

Keyword: Customary law, customary title, Customary Institution

\section{Pendahuluan}

Sejarah mencatat kelahiran negara modern sejak abad 7 dan 8 yaitu masa feodalisme, terus tumbuh dan berkembang melewati abad - abad ke 12, 15, 17 sampai puncaknya pada abad 19 dengan konsep rule of law (common 
law system), rechstaaat (civil law system) dan negara konstitusional, perkembangan ini juga berbarengan dengan sejarah sosial budaya negara eropa, Eropa Barat khususnya, yakni merangkak dari dark-ages, middle ages, renaisancce 'pencerahan' dan akhirnya sampai ke abad modern. ${ }^{1}$

Mulai saat itu hukum memasuki hampir semua ranah kehidupan manusia dan membangun bentuk ketertiban yang diinginkannya, hampir tidak ada ranah kehidupan yang tidak diatur oleh model hukum ini, hukum melakukan intervensi dalam kehidupan manusia. Kehidupan penuh dengan keteraturan, tidak ada lagi yang berjalan alami dan mandiri, hukum pelan pelan mensegmentasi kehidupan manusia, mulai dari ranah kesehatan, ekonomi, sosial budaya, pendidikan, semuanya dibagi - bagi sesuai dengan alur yang di kehendakinya dalam bentuk aturan - aturan yang harus dipatuhi dan dijalakan sebagai pedoman kehidupan. Kenyataan dan kebenaran sekalipun dikonstruksi mengikuti kemauan dan kehendak hukum tersebut.

Dalam logika hukum modern
yang dianggap hukum adalah
keputusan badan - badan yang
berwenang, diluar itu tidak dianggap
hukum, kecuali memperoleh izin dari

1Satjipto Rahadjo, Biarkan Hukum Mengalir: Catatan Kritis Tentang Pergulatan Manusia dan Hukum, Jakarta: Penerbit Kompas, 2007, hal. 106.

http://dx.doi.org/10.18592/sy.v18i2.2140 hukum negara tersebut, aturan - aturan yang telah ada sebelumnya seperti tatanan kearifan lokal atau hukum adat (living law) hanya akan berlaku apabila hukum negara tegas memberi izin untuk itu. $^{2}$

Indonesia sebagai negara yang mengadopsi sistem hukum modern lewat pencaplokan atau aneksasi dan transplantasi budaya yang berlangsung lebih dari satu abad (1840 - 1950), yang kemudian berlanjut dengan proses modifikasi serta adaptasinya.$^{3}$ Seperti diungkapkan oleh Sir Stamford Raffles dalam History Of Java, Kebanyakan masyarakat indonesia punya sedikitnya artikulasi kebudayaan antara Budhisme, Hinduisme, Islamisme, Konfusianisme, dan seterusnya. Setelah itu, muncul silang kebudayaan dengan Portugis, Spanyol, Belanda dan Inggris. Namun, watak dasar bangsa Indonesia, tetaplah keutuhan dari sebuah keluarga, sebuah pilihan hidup yang mistis dan spuritual (total mystical experience of anones). ${ }^{4}$

Kodifikasi dan unifikasi hukum modern yang dilakukan tidak saja berimbas pada perubahan struktur dan

2 Rahardjo, Satjipto, Dalam Khudzaifah Dimyati (ed), 2004, Ilmu Hukum: Pencarian Pembebasan dan Pencerahan, Surakarta: Muhammadiyah Univesity Press Ubiversitas Muhammadiyah Surakarta. hal. 24.

${ }^{3}$ Soetandyo Wignjosoebroto, Dari Hukum Kolonial Ke Hukum Nasional: Dinamika SosialPolitik Dalam Perkembangan Hukum Indonesia, Jakarta: PT. Raja Grafindo Persada, edisi 1cetakan kedua1995, hal. 111.

4 Jimly Asshiddiqie dkk. Supomo : Pergulatan Tafsir Negara Integralistik. Penerbit Thafa Media. Yogyakarta : 2015. Hal 66. 
sistem penegakan hukum, namun juga berefek pada dinamika kearifan lokal yang tumbuh dan berkembang ditengah - tengah masyarakat. Masyarakat Indonesia didesak dan dipaksa untuk menerapkan hukum yang jauh bahkan berbeda sama sekali dengan budaya dan kultur mereka, negara - negara berkembang seperti Indonesia harusnya tidak bisa dipaksakan cara - cara penyelenggaraan hukum yang mapan seperti di barat. ${ }^{5}$

Setelah lama dalam menjalankan hukum modern ( hukum positif ) ini Indonesia ternyata harus merasakan ketidaknyamanan dengan sistem itu, karena justru hukum modern (paradigma positivistik) yang diberlakukan diseluruh Nusantara menjadi 'beban pranata lokal', hukum dirasakan menjadi beban berat untuk dijalankan, malah menjadi benda asing bagi sebagian besar masyarakat Indonesia. Janji - janji hukum modern seperti justice for all malah yang di saksikan justive not for all. 7 Bolaang Mongondow Raya (Bolaang Mongondow, Bolaang Mongondow Utara, Bolaang Mongondow Selatan, Bolaang Mongondow Timur dan Kota Kotamobagu ) merupakan daerah yang

5 Khudzaifah Dimyati, Teorisasi Hukum: Studi Tentang Perkembangan Pemikiran Ilmu Hukum Di Indonesia 1945-1990, Yogyakarta: Genta Publishing, cetakan kedua 2010, hal. 99.

6 Rahadjo, Satjipto, Penegakan Hukum Progresif, Jakarta: Kompas, 2010, hal. 6.

${ }_{7}$ FA. Adji Samekto, Justice Not For All: Kritik Terhadap Hukum Modern Dalam Perspektif Studi Hukum Kritis, Yogyakart: Genta Press, 2008, hal. 12. merasakan dampak ketidaknyamanan dari paradigma positivistik ini dan kemudian meminggirkan nilai adat istiadat didaerah ini. Bolaang Mongondow Raya atau yang sering disingkat BMR ini belum resmi menjadi daerah otonomi baru, tapi sudah disebutkan dalam surat Usul Pembentukan Daerah Otonom Baru Provinsi Bolaang Mongondow Raya dengan nomor surat 100/2061/Sekr.Rp.Pemhumas tertanggal 28 Juli 2016. Bolaang Mongondow menjadi nama wilayah ini sebelum terjadi pemekaran adalah bagian dari Sulawesi Utara.

Jurnal yang berjudul The History Of Islam In Bolaang Mongondow, North Sulawesi Rationalisation and derationalisation of religion menjelaskan bahwa Bolaang Mongondow is in the province of North Sulawesi. It shares its northeasternborder with the Minahasa region - well known as a stronghold of Protestant Christianity - and its western border with Gorontalo which has special pride in its long bistory of Islamic influence dating before the arrival of the first Europeans. ${ }^{8}$ Wilayah Bolaang Mongondow Raya yang merupakan bagian dari Sulawesi Utara dan dalam jurnal ini disebutkan sebagai Bolaang Mongondow yang berbatasan dengan Minahasa dan Gorontalo. Minahasa merupakan daerah dengan mayoritas pemeluk agama Protestan

8 Sven Kosel, 2010. The History Of Islam In Bolaang Mongondow, North Sulawesi Rationalisation and derationalisation of religion, Journal : Indonesia and the Malay World Vol. 38. 43-64. 
sementara Gorontalo merupakan daerah dengan dominasi Pemeluk agama Islam yang besar tidak menjadikan daerah Bolaang Mongondow Raya sebagai daerah yang memiliki Adat Istiadat yang sama persis dengan salah satu daerah terdekatnya. Bolaang Mongondow Raya Memiliki Budaya dan Adat Istiadatnya sendiri.

Undang - Undang Dasar Negara Republik Indonesia 1945 pasal 18 B ayat 2 menjelaskan tentang penghormatan Negara Republik Indonesia atas Adat Istiadat yang hidup dan berkembang ditengah masyarakat. Pengakuan ini merupakan bentuk keleluasaan Pemerintah Daerah dan seluruh masyarakat untuk menjalankan semua prosesi adat selama itu tidak bertentangan dengan kepentingan Negara Republik Indonesia. Undang undang ini merupakan representasi dari bagitu banyaknya suku dan budaya yang ada di indonesia yang tidak boleh hilang. Hal ini dijelaskan dalam Jurnal yang berjudul Velue In Executing Tumbilo Tohe ( Part Of Light) Each Of Ramadan As One Manifestation Of The Parctice Of Pancasila By People Gorontalo yang menyebutkan bahwa In indonesia there are bundreds or tribes, whose culture must be multifaceted and should still be preserved according to the sound of article $18 \mathrm{~B}$ amandement to the constitution of $1945 .{ }^{9}$

9 Johan Jasin, 2015. Velue In Executing Tumbilo Tohe ( Part Of Light) Each Of Ramadan As One Manifestation Of The Parctice Of Pancasila By People Gorontalo, Jurnal : Journal Of Humanity, III, (1), 1-11.
Pasal 28 I ayat 3 menyebutkan bahwa "Identitas budaya dan hak masyarakat tradisional dihormati selaras dengan perkembangan zaman dan peradaban"10 yang kemudian di dukung dengan Pasal 32 ayat 1 yang menyebutkan "Negara memajukan kebudayaan nasional Indonesia di tengah peradaban dunia dengan menjamin kebebasan masyarakat dalam memelihara dan mengembangkan nilainilai budayanya"11. Pengakuan Negara lewat Undang - Undang atas rasa hormatnya yang berulang kali atas Adat Istiadat dalam Undang - Undang Dasar Negara Republik Indonesia 1945 ini seharusnya diteruskan oleh Pemerintah Daerah di Bolaang Mongondow Raya sebagai atribusi wewenang untuk mengambil langkah mandiri dalam melestarikan Adat Istiadat diwilayah Bolaang Mongondow Raya.

$$
\text { Kenyataan yang terjadi }
$$
dilapangan sangatlah jauh dari harapan. 4 kabupaten dan 1 kota yang tergabung dalam wilayah Bolaang Mongondow Raya tidaklah nampak langkah nyata dalam perlestarian Adat Istiadatnya. Bahkan sampai saat ini belum pernah terlihat ataupun terdengar langkah pasti pelestarian adat dan tradisi yang begitu banyak didaerah ini. Misalnya adat Pernikahan, Kematian, Musyawarah dan lain - lain yang dihimpun dalam 1 kompilasi Hukum Adat Bolaang 
Mongondow Raya atau setidaknya dimasing - masing kabupaten dan kota madya yang tergabung didalamnya, dari begitu banyak prosesi Adat Istiadat yang ada di wilayah Bolaang Mongondow Raya, peneliti mengambil fokus masalah pemberian Gelar Adat.

\section{Manfaat Penelitian}

Pemberian Gelar Adat adalah
prosesi sakral kedaerahan yang
seharusnya dilaksanakan oleh
Pemerintah Daerah dari proses seleksi yang terbuka dan dengan tahapan tahapan yang jelas. Seharunya pemberian Gelar Adat menjadi tanggung jawab pemerintah malah menjadi pekerjaan LSM. Sejak 3 tahun terakhir, terhitung sudah 3 kali LSM memberikan Gelar Adat. ${ }^{12}$ Pemberian Gelar adat ini dianggap kurang tepat karena syarat akan kepentingan kelompok tertentu. Disisi lain, Pemberian Gelar Adat yang tidak melalui prosedur yang jelas mengakibatkan rasa hormat atas orang yang menerima gelar adat tidak begitu terasa dikalangan masyarakat. Penelitian ini diharapkan menjadi referensi tentang Gelar Adat diwilayah Bolaang Mongondow Raya, menjadi langkah pelestarian Adat Istiadat Bolaaang Mongondow Raya.

12

http://www.awdisulutnews.com/2016/07/watu ng-disambut-masyarakat-bolaang.html . Di akses tanggal 7 mei 2017, $23: 15$ Wita.

\section{Metode dan Bahan}

Penelitian ini adalah penelitian empiris dengan populasi seluruh masyarakat Bolaang Mongondow Raya sementara memiliki sampel yaitu Bupati, Ketua DPRD dan 1 Tokoh Adat di seluruh kabupaten dan kotamadya yang tergabung dalam wilayah Bolaang Mongondow Raya, ditambah dengan Ketua LSM Amabom ( Aliansi Masyarakat Adat Bolaang Mongondow ) sebagai pemberi gelar adat. Sampel dengan jumlah 16 orang ini dianggap cukup oleh peneliti dalam memberikan keterangan tentang Peran Pemrintah melestarikan pemberian Gelar di Bolaang Mongondow Raya. Penelitian ini menggunakan 2 pendekatan, yaitu pendekatan perundang - undangan dan pendekatan comparative ( perbandingan ). Bahan yang digunakan untuk penelian ini adalah hasil wawancara dan studi dokumentasi juga kepustakaan yang mendukung hasil wawancara dilapangan.

\section{Gelar Adat di Bolaang Mongondow Raya}

Pemberian gelar adat di Bolaang Mongondow erat kaitannya dan berpengaruh langsung dengan 4 eks swapraja yang tergabung dalam Bolaang Mongondow Raya bukan hanya untuk kabupaten Bolaang Mongondow saja. ${ }^{13}$ Pemberian gelar

13 Wawancara chairun mokoginta di Genggulang, 10 Desember 2017 
adat di Bolaang Mongondow Raya tidak hanya diberikan kepada orang yang masih hidup saja, tetapi kepada orang yang sudah meninggalpun ada yang mendapatkan Gelar Adat. Sejarah pemberian Gelar Adat Bolang Mongondow Raya dimulai pada 1303 kepada Datu Binangkang kemudian berlanjut pada 1493 masa kepemimpinan Kinalang Damopolii, kinalang sendiri berarti yang didoakan.

Pada dasarnya Gelar Adat itu merupakan nama. Didaerah Bolaang Mongondow Raya dikenal ada 3 nama yang melekat pada seseorang. Nama nama tersebut ialah :

1. Tangoi No'i Donoi atau nama yang melekat sebagai nama keseharian atau nama panggilan sehari - hari. Nama ini bisa berubah - rubah tergantung dari status seseorang apakah sudah memiliki keturunan atau belum. Misalnya nama panggilan seseorang adalah Un, setelah dia memiliki anak dengan nama Ika, maka namanya Akan berubah menjadi Ama’i Ika ( Bapakmya Ika ), kemudian setelah dia memiliki cucu bernama Rafi, namanya berubah lagi menjadi Laki’i Rafi ( Kakekya Rafi). Nama anak dan cucu pertamalah yang biasanya disematkan tersebut.

2. Tangoi No'i Tombuloi atau nama yang disematkan sejak lahir.
Yang melekat sampai mati misalnya nama sesuai Akte kelahiran.

3. Tangoi No'i Simpoloy yang melilit sewaktu waktu bisa dibuka. Nama inilah yang digolongkan sebagai Gelar Adat. Nama ini diberikan oleh para tetua adat dan dapat dilepaskan ketika melakukan sesuatu yang melanggar O'Adatan atau Adat Istiadat.

Hukum merupakan sebuah sistem nilai. Menurut Satjipto Raharjo, hukum sebagai perwujudan nilai - nilai yang mengandung arti bahwa kehadiran hukum adalah untuk melindungi dan memajukan nilai - nilai yang dijunjung tinggi oleh masyarakat. ${ }^{14}$

Sesuai pendapat Satjipto Raharjo diatas, peneliti menemukan sebuah nilai luhur yang terkandung didalam Gelar Adat yang ada diwilayah Bolaang Mongondow Raya. Gelar yang digolongkan sebagai Tangoi No'i Simpoloy atau nama yang melekat diibaratkan seperti selendang kebesaran atau bunga yang dikalungkan kepada seseorang sebagai tanda kehormatan adat dan harus dihormati oleh seluruh masyarakat diwilayah Bolaang Mongondow Raya. Namun bisa dilepas jika terjadi hal - hal yang di anggap melanggar Adat Bolaang Mongondow Raya.

14 Satjipto Raharjo. Sosiologi Hukum. Jogjakarta. Genta Publishing :2015. Hal 66. 
Jepang merupakan negara dan bangsa yang memiliki strukturasi masyarakat berdasarkan nilai dan moral komunal. Negara - negara yang menonjolkan asas komunalitas di Asia Timur seperti Korea bahkan Indonesia sendiri menjunjung asas tersebut. ${ }^{15}$ Jepang dalam srtukturisasinya menempatkan diri sebagai negara moderen yang menjadikan kearifan lokalnya sebagai landasan besar untuk menjalankan sebuah sistem hukum. Hal ini kemudian membawa Jepang sebagai negara maju yang tidak sama dengan negara - negara eropa yang individulis, tapi menjadikan Jepang sebagai negara maju yang tetap menjaga kebudayaannya.

Di Indonesia sendiri terkhusus di Bolaang Mongondow Raya, Nilai moral tertanam sangat dalam dihati sanubari masyarakatnya. Pemberian gelar merupakan sebuah amanah dari masyarakat kepada penerima gelar untuk menjaga nama baik dari daerah ini. Gelar adat yang diberikan kepada Penerima gelar adat Oleh Tertua Adat, apapun Gelar Adat di Bolaang Mongondow Raya dilihat dari sudut pandang Objek Penerima Gelar Adat untuk yang masih hidup dan yang sudah meninggal adalah sebagai berikut;

\section{Pemberian Gelar Adat Kepada Yang Sudah Meninggal.}

15 Ibid hal 70.
Damopolii adalah Punu' atau pimpinan wilayah mongondow yang ke 4 yang dianugerahkan gelar adat Kinalang. ${ }^{16}$ Prosesi pembertian gelar adat kinalang memakan waktu hingga 40 hari. Dalam adat kebudayaan Bolaang Mongondow Raya pelaksanaan adat kematian pada umumnya dilaksanakan pada malam malam tertentu yang dikenal dengan sebutan Gobiianya atau Malam malamnya yaitu pelaksanaan adat kematian pada malam - malam yang sudah ditentukan, misalnya Tolu gobi'i atau malam ketiga, Pitu gobi'i atau malam ketujuh , kodua pitu atau Malam ke 14, opat nopulu' no gobi'i atau 40 malam, dan tompod mogatut atau 100 hari ditandai dengan Momilat kon Aluwang atau melepaskan seledang putih yang menjadi simbol sedang dilanda duka yang disematkan di pundak ahli duka (khusus keluarga dekat dengan jenis kelamin perempuan). ${ }^{17}$

Terkhusus untuk prosesi pemberian Gelar Adat kematian (Kalangon) kepada pemimpin atau Kinalang (yang di doakan) dilaksanakan selama 40 hari yang setiap harinya dilaksanakan penyembelihan hewan. Setelah Raja atau pemimpin daerah dinyatakan meninggal, maka dibuatkanlah bangunan khusus dengan tinggi minimal 4 meter dan berbentuk

16 H.J,A. Damopolii, DODANDIAN : Kinotanoban dan Kisabku. Kotamobagu : yayasan Ibnu Sabil. 2003. Hal 15.

${ }^{17}$ Wawancara Bapak Delianto Bengga), di Passi 12 Desember 2017. 
seperti menara yang disebut dantagan kemudian jenazahnya diletakkan diatas menara tersebut bersama dengan seluruh pakaiannya dan dibungkus dengan kain berwarna putih. Dibawah bangunan yang menyerupai menara tersebut dilakukan dete - detei atau nyanyian duka oleh pemangku adat dan pelayat duka.

Jenazah kinalang akan diturunkan dan dikebumikan manakala telah selesai semua prosesi adat kematian dan Bobuligan (keranda Jenazah) dibuat. Keranda yang terbuat dari bambu utuh yang hanya di keluarkan ujung daun - daunya tersebut akan dikuburkan bersamaan dengan jenazah kinalang tersebut. Berbeda dengan upacara kematian untuk masyarakat biasa yang memiliki sebutan tonggoluan (diistirahatkan). Prosesi pelaksaan Adat kematian biasa ini hanya dilaksanakan Mintahang (Doa Arwah) tanpa prosesi besar seperti pembuatan bangunan tinggi dan keranda istimewa. ${ }^{18}$

40 hari pelaksaan adat Kalangong, pada setiap harinya dilaksanakan Mintahang setelah jenazah dikebumikan. Mintahang ini dipimpin oleh pemuka adat. Sebelum prosesi mintahang dimulai, maka semua makanan yang disediakan diletakkan diatas dantangan. Makanan tersebut kemudian akan diperebutkan oleh

18 Wawancara Chairun Mokoginta, Genggulang 10 Desember 2017 masyarakat setelah prosesi mintahang selesai.

Pemberian Gelar Adat kepada orang yang sudah meninggal dianggap lebih layak dilaksanan dibandingkan dengan pemberian Gelar Adat kepada orang yang masih hidup. Menurut Delfian Thanta, staf dinas Kebudayaan dan Pariwisata Kabupaten Bolaang Mongondow Selatan, pemberian Gelar Adat pernah diberikan kepada Raja Van Gobel setelah beliau meninggal. Pemberian Gelar Adat Kepada orang yang berjasa dan sudah meninggal dianggap lebih layak dengan alasan gelar tersebut merupakan sebuah hadiah yang berharga atas jasa seseorang semasa hidupnya. ${ }^{19}$ Pemberian Gelar Adat eks Swapraja Bolango selama ini belum pernah diberikan kepada orang yang masih hidup terkhusus untuk wilayah Bolaang Mongondow Selatan.

Pemberian gelar untuk orang yang sudah meninggal layaknya seperti gelar Pahlawan Nasional di Negara Kesatuan Republik Indonesia. Gelar pahlawan itu diberikan atas kinerja maupun jasa orang tersebut kepada negara Kesatuan Republik Indonesia. Rita Lamusu, Anggota Dewan Provinsi Sulawesi Utara, Dapil Bolaang Mongondow Raya menjelaskan bahwa yang lebih layak menerima Gelar Adat adalah mereka yang sudah meninggal

19 Wawancara Delfian Thanta, Dinas Kebudayaan dan Pariwisata Bolaang Mogondow Selatan, 7 desember 2017. 
dan banyak jasanya untuk daerah Bolaang Mongondow Raya. Pemberian Gelar Adat kepada orang yang sudah meninggal akan menghindari terjadinya pemberian Gelar Adat kepada orang yang salah atau dengan kata lain pemberian Gelar Adat tersebut tidak akan mendatangkan rasa malu kepada masyarakat Bolaang Mongondow Raya karena diberikan diakhir hayat, ditakutkan penerima Gelar Adat melakukan tindakan yang memalukan. ${ }^{20}$

\section{Pemberian Gelar Adat Kepada Orang Yang Masih Hidup.}

Sejarah Bolaang Mongondow telah mencatat, ada beberapa pejabat yang telah menerima Gelar Adat, yang langsung dilakukan dengan prosesi adat. menurut Ketua Amabom, Bapak Jemmy Lantong, yang pernah menyandang Gelar kehormatan atau Gelar Adat Bolaang Mongondow adalah sebagai berikut :

1. Punu Mokodoludut dengan gelar Punu' Gumolong, tahun 1303. Punu' berarti Pemimpin sementar Guomolong nerasal dari kata Golong yaitu potongan kayu, Dari cerita rakyat yan gsampai saat ini dipercaya oleh masyarakat

Bolaang Mongondow, Punu Mokodoludut adalah Raja yang

20 Wawancara Rita Lamusu, Dirumahnya Desa Tobongon Bolaang Mongondow Timur, 12 Desember 2017 ditemukan hanyut bersama potongan kayu disungai Tumpa.

2. Salamatiti ( Ibu dari Mokodoludut ) dengan gelar Boki'. Boki' berarti permaisyuri.

3. Silagondo dengan gelar Boki'. Boki' berarti permaisyuri.

4. Mayor Oe. N. Mokoagow Mantan Bupati 1966 - 1976 ) dengan gelar Tonawat In Totabuan, tahun 1970. Dalam arsip Pribadi Alm. Benard Ginupit yang berjudul Kamus Mongondow - Indonesia kata Tonawat berarti Seseorang yang mengetahui Ilmu Perbintangan untuk menemukan musim, mengenal ilmu ilmu obat obatan tradisional sehingga dianggap sebagai tokoh masyarakat. Sementara Totabuan berarti tempat tinggal atau kediaman, dari arti kata diatas maka Tonawat In totabuan memiliki arti Tokoh yang memiliki banyak ilmu pengetahuan ditanah Bolaang Mongondow.

5. Istri Mayor Oe. N. Mokoagow dengan gelar Boki' In Totabuan, tahun 1970. Boki'in Totabuan berarti permaisyuri ditanah Bolaang Mongondow.

6. Drs. A. J. Sondakh dengan gelar Ki Sinungkudan, tahun 2005. Sinungkudan berasal dari kata Tungkud yang berarti Tongkat, maka dari itu Ki Sinungkudan memiliki arti yang diberikan 
tongkat atau yang memegang kekuasaan tertinggi.

7. Letjen Purn. G. H. Mantik ( Mantan Guberbur Sulut 1980 1985 ) dengan gelar Tonggulu Goba', tahun 2005. Tunggulu berarti mengepalai atau menguasai sementara Goba' berarti perkebukan atau pertanian, Tonggulu Goba berarti orang yang yang menguasai masalah pertanian sdan perkebunan.

8. Hj. Marlina Moha Siahaan ( Mantan Bupati Bolaang Mongondow 2001 - 2011, Sebelum pemekaran ) dengan gelar Boki' Kolano Inta Nolintak Kon Totabuan. Nolintak berasal dari kata Lintak yang memiliki arti tinggi, Nolintak berarti Meninggikan. Boki' Kolano Inta Nolintak Kon Totabuan Memiliki arti permasyuri raja yang meninggikan derajat tanah kelahiran.

9. Drs. Hi. Depri Pontoh (Bupati Bolaang Mongondow Utara 2013 -2018) dengan gelar kidoni Panggulu, tahun 2013. kidoni Panggulu memiliki arti Petinggi Distrik.

10. Suriansyah Korompot, S.H. (Wakil Bupati Bolaang Mongondow Utara 2013 -2018) dengan gelar kidoni Panggulu, tahun 2013. kidoni Panggulu memiliki arti Petinggi Distrik.
11. Jasmine Tongi (Sangadi Tanoyan Utara 2013 - 2019) dengan gelar Ki Sinungkudan. Sinungkudan berasal dari kata Tungkud yang berarti Tongkat, maka dari itu Ki Sinungkudan memiliki arti yang diberikan tongkat atau yang memegang kekuasaan tertinggi.

12. AKBP Hisar Siallangan, SIK (Kapolres Bolaang Mongondow 2012 -2014) dengan gelar Itoy Adat. Itoy Adat berarti Petinggi atau Pembesar Adat.

13. Letkol M. Jamaludin Malik, SIP ( Dandim 1303 Bolaang Mondondow 2012 -2014 ) dengan gelar Itoy Adat. Itoy Adat berarti Petinggi atau Pembesar Adat.

14. Drs. Sony Sumarsono, MDM Pjs Gubernur Sulut 2014 -2015 ) dengan gelar Punu Molantud. Punu Molantud berarti Pimpinan Tertinggi.

15. Fien Ering, S.H, M.H. ( Kejari Kotamobagu 2012 - 2015 ) dengan gelar Itoy Adat. Itoy Adat berarti Petinggi atau Pembesar Adat.

16. Brigjen Pol Drs. Wilmar Marpaung, S.H. (Kapolda Sulut 2015 - 2016) dengan gelar Bogani In Totabuan. ${ }^{21}$ Bogani memiliki orang yang kuat yang mampu mengayomi dan menjaga masyarakat. Bogani In

21 Wawancara dengan Ketua Amabom, Motoboi Kecil, 12 Desember 2017. 
Totabuan memiliki arti pengayom dan pelindung ditanah kelahiran.

Pemberian Gelar Adat juga pernah diberikan kepada Punu' Mokoagow dan Loloda Mokoagow, pemberian gelar kepada keduanya dinilai merupakan pemberian gelar yang paling sakral oleh bapak Chairun Mokoginta. ${ }^{22}$ Adapun pemberian gelar yang dilakukan oleh pemangku adat dari utusan desa - desa di Bolaang Mongondow pernah dilakukan dimasa sekarang, yaitu pemberian gelar adat kepada Hj. Marlina Moha Siahaan. Pemberian Gelar Adat itu sama kriterianya dengan pemilihan Bogani ( Pemimpin wilayah ) dimasa kerajaan. Adapun dalam pemilihan Bogani, kandidat Bogani harus memiliki kriteria sebagai berikut : ${ }^{23}$

1. Mokodotol, berjiwa patriotik memiliki fisik dan bentuk tubuh yang kuat, sehat dan tangguh.

2. Mokorakup, menjadi pengayom yang dapat memahami dan menyelesaikan semua masalah diwilayah kepemimpinanya.

3. Mokodia, mampu menjalankan sangsi adat kepada orang terdekat sekalipun.

4. Mokoanga', memiliki karisma besar dan dapat menjaga sikap dan perilakunya dari sejak dini.

5. Memiliki kekuatan supranatural.

22 Wawancara Chairun Mokoginta, Genggulang 10Desember 2017

${ }^{23}$ Ibid.
Dalam kriteria yang telah disebutkan, terkhusus untuk kriteria penerima Gelar Adat dimasa sekarang tidak lagi ada syarat yang terakhir disebutkan diatas yaitu memiliki kekuatan supranatural, akan tetapi yang dilihat adalah sumbangsihnya kepada daerah Bolaang Mongondow Raya. Hal ini terlihat jelas pada pemberian gear adat untuk Hj. Marlina Moha Siahaan yang berhasil melakukan pemekaran daerah Bolaang Mongondow, menjadi 4 kabupaten dan 1 kotamadya. 24 Walaupun pada dasarnya Siahaan bukanlah Marga Asli Bolaang Mongondor Raya.

Pemberian Gelar Adat dianggap layak dilaksanakan ketika seseorang jelas telah berjasa untuk membangunan daerah Bolaang Mongondow. Misalnya penganugerahan gelar kepada Letjen Purn. G. H. Mantik (Mantan Guberbur Sulut 1980 - 1985 ) dengan gelar Tonggulu Goba', tahun 2005. Pemberian gelar ini di anggap layak dengan alasan bahwa bapak G. H. Mantik berhasil menjadikan Bolaang Mongondow sebagai daerah penghasil beras terbesar di Sulawesi Utara dan berhasil swasembada pangan saat itu. ${ }^{25}$

Gelar Adat dapat diberikan kepada orang asli Bolaang Mongondow maupun orang dari luar Bolaang Mongondow. Jasa besar dan kinerja

${ }^{24}$ Ibid.

25 Wawancara Bapak Sehan Ambaru, di Dinas kebudayaan dan Pariwisata Kota Kotamobagu.11 Desember 2017. 
untuk membesarkan Bolaang Mongondow layak diapresiasi dengan Gelar Adat tersebut. Pemberian Gelar Adat tidak sepatutnya diberikan kepada orang yang baru datang untuk meduduki jabatan tertentu karena tugas negara walaupun itu jabatan yang tinggi, agar tidak tampak bahwa Gelar Adat wilayah Bolaang Mongondow Raya murah dimata mereka para pemerhati adat yang lain. ${ }^{26}$

Peneliti menemukan bahwa dalam mekanisme pemberian Gelar Adat di Bolaang Mongondow Raya belum memiliki format yang disepakati oleh semua pihak yang berkompeten didalam pemberian Gelar Adat itu sendiri. Namun dari keterangan narasumber, bahwa dalam mekanisme pemberian gelar adat seharunya melibatkan seluruh pelaku adat di desa - desa, karena pelaku adat yang tersisa dilingkup Bolaang Mongondow Raya tinggallah di desa - desa. ${ }^{27}$

Langkah - langkah yang pernah ditempuh dalam pemberian gelar adat yang dianggap paling cocok karena pernah berlaku dimasa kepemimpinan Hj. Marlina Moha Siahaan semasa menjabat sebagai bupati Bolaang Mongondow sebelum pemekaran untuk diterapkan sekarang adalah ${ }^{28}$

\footnotetext{
26 Wawancara Bapak Drs. Jainudin Damopolii. Kotamobagu, 11 Desember 2017.

27 Wawancara Chairun Mokoginta, Genggulang 10 Desember 2017 ${ }^{28}$ Ibid
}

1. Merekomendasikan penerima gelar adat pada pimpinan tertinggi Adat yaitu Bupati atau Walikota (siapa saja boleh merekomendasikan dan dengan alasan yang jelas ).

2. Walikota atau Bupati mengumpulkan seluruh lembaga adat dari desa desa untuk membahas kelayakan penerima gelar adat.

3. Jika disepakati bahwa orang yang direkomendasikan layak menerima Gelar Adat, maka diumumkan kepada masyarakat tentang waktu prosesi pemberian gelar adat agar semua dapat menyaksikkanya.

4. Penyerahan Gelar Adat kepada penerima gelar sesuai prosesi adat istiadat dan dilakukan secara terbuka untuk umum.

\section{Peran Pemerintah dalah Pelestarian Adat Istiadat.}

Provinsi Gorontalo lewat Perda Nomor 2 tahun 2016 tentang Penyelenggaraan Lembaga Adat ${ }^{29}$ menegaskan bahwa seluruh kegiatan Adat istiadat merupakan kewenangan dari Lembaga Adat Provinsi gorontalo,

${ }^{29}$ Petaruran Daerah Provinsi Gorontalo Nomor 2 Tahun 2016 Tentang Penyelenggara Lembaga Adat. 
dengan aturan ini maka Lembaga Adat memiliki tugas dan fungsi yang jelas dalam kegiatan pelestarian Adat Istiadat termasuk pemberian Gelar Adat, sementara di wilayah Bolaang Mongondow Raya belum ada satupun daerah yang memberikan kewenangan penyelengaraan Adat Istiadat Lewat Perda kepada lembaga adat. Perda Lembaga Adat sangat dibutuhkan agar langkah pelestarian Adat Istiadat tidak terkendala pada tidak adanya pelaksana yang memang memiliki tugas khusus untuk pelestarian Adat Istiadat.

Penganugrahan Gelar Adat diwilayah Bolaang Mongondow Raya dewasa ini menjadi polemik panjang dikalangan budayawan. Pemberian gelar adat yang dilaksanakan oleh LSM oleh sebagian besar budayawan dianggap sebagai sebuah kegiatan yang melanggar O'Adatan karena tidak merepresentasikan seluruh masyarakat Bolaang Mongondow Raya sementara Gelar Adat merupakan prosesi tertinggi dan harus dihormati seluruh masyarakat. Bahkan pemberian Gelar Adat yang 3 tahun terakhir dilaksanakan oleh AMABOM ( Aliansi Masyarakat Adat Bolaang Mongondow ) tidak ada campur tangan sama sekali oleh Pemerintah Daerah, adapun bantuan yang datang dari para pejabat daerah seperti Bupati dan Walikota merupakan bantuan mengatas namakan individu bukan jabataannya sebagai pimpinan tertinggi daerah. ${ }^{30}$. Misalkan saja dalam pemberian Gelar Adat kepada mantan PJS Gubernur Sonny Sumarsono, para Bupati dan Walikota memberikan sumbangsih secara langsung kepada Amabon mengatas namakan pribadi mereka sendiri, bukan sebagai pejabat pemerintah. Langkah mandiri yang ditempuh oleh LSM ini dianggap perlu untuk membangkitkan rasa peduli masyarakat pada adat istiadat yang mulai ditinggalkan, walaupun melahirkan perdebatan panjang tentang layak tidaknya LSM mengambil alih kegiatan adat yang sakral di Bolaang Mongondow Raya taitu pemberian Gelar Adat.

Atribusi kewenagan lewat Undang - Undang Dasar Negara Republik Indonesia, mengenai adat istiadat sudah seharusnya dijadikan dasar oleh Pemerintah daerah di wilayah Bolaang Mongondow Raya untuk segera membuat peraturan daerah dari masing - masing kabupaten dan kotamadya tentang Lembaga adat, atau Peraturan daerah bersama tentang Lembaga adat mengingat 4 eks swapraja yang tergabung didalam wilayah Bolaang Mongondow Raya pernah disatukan menjadi Kabupaten Bolaang Mongondow dengan perjanjian para Raja Raja untuk patuh dalam 1 payung adat Bolaang Mongondow. ${ }^{31}$ Lembaga Adat

30 Wawancara bapak Jemmy Lantong , Motoboi Kecil 12 Desember 2017.

31 Wawancara Chairun Mokoginta, Genggulang 10 Desember 2017 
yang memiliki kekuatan hukum akan menjadi titik tengah antara konflik kepentingan dari LSM dan para budayawan yang tidak tergabung kedala LSM Adat yang ada di Bolaang Mongondow Raya.

\section{Kesimpulan}

Gelar adat diwilayah Bolaang Mongondow Raya terbagi menjadi 2 dilihat dari sudut pandang Objek penerima Gelar Adat, yaitu Gelar adat untuk orang yang sudah meninggal misalnya diberikan kepada Damopolii yaitu Kinalang dan kepada Raja Van Gobel di eksswapraja Bolango, Gelar Adat untuk yang masih Hidup yang dianugrahkan kepada Mokodoludut hingga Brigjen Pol Drs. Wilmar Marpaung, S.H. pada tahun 2016.

Atribusi kewenangan oleh Undang Undang Dasar egara Republik Indonesia tentang adat sudah seharusnya segera ditindak lanuti oleh masing masing daerah sebagai langkah pelestarian adat istiadat. Provinsi Gorontalo yang menjadi tetangga terdekat Wilayah Bolaang Mongondow Raya sudah mengesahkan Perda tentang Penyelenggaraan Lembaga Adat pada tahun 2016. Perda tentang Lembaga adat dianggap perlu untuk menjaga Kelestarian Budaya yang semakin terkikis oleh perkembangan zaman yang semakin modern, dan menghindari konflik konflik kepentingan dari kelompok kelompok yang mengaku peduli dengan Adat istiadat Bolaang Mongondow Raya.

\section{Daftar Pustaka}

- Buku

FA. Adji Samekto, 2008, Justice Not For All: Kritik Terbadap Hukum Modern Dalam Perspektif Studi Hukum Kritis, Yogyakart: Genta Press.

H.J,A. Damopolii, 2003. DODANDIAN : Kinotanoban dan Kisabku. Kotamobagu : yayasan Ibnu Sabil.

Jimly Asshiddiqie dkk. 2015. Supomo : Pergulatan Tafsir Negara Integralistik. Penerbit Thafa Media. Yogyakarta.

Khudzaifah Dimyati, cetakan kedua 2010. Teorisasi Hukum: Studi Tentang Perkembangan Pemikiran Imu Hukum Di Indonesia 1945. 1990, Yogyakarta: Genta Publishing.

Rahadjo, Satjipto, 2010, Penegakan Hukum Progresif, Jakarta: Kompas. Rahardjo, Satjipto, Dalam Khudzaifah Dimyati (ed), 2004, Ilmu Hukum: Pencarian Pembebasan dan Pencerahan, Surakarta: Muhammadiyah Univesity Press Ubiversitas Muhammadiyah Surakarta.

Rahadjo Satjipto, 2007. Biarkan Hukum Mengalir: Catatan Kritis Tentang Pergulatan Manusia dan Hukum, Jakarta: Penerbit Kompas.

Raharjo Satjipto, 2015.. Sosiologi Hukum. Jogjakarta. Genta Publishing. 
Soetandyo Wignjosoebroto, , edisi 1 cetakan kedua1995. Dari Hukum Kolonial Ke Hukum Nasional: Dinamika Sosial-Politike Dalam Perkembangan Hukum Indonesia, Jakarta: PT. Raja Grafindo Persada.

- Jurnal

Johan Jasin, 2015.Velue In Executing Tumbilo Tohe ( Part Of Light) Each Of Ramadan As One Manifestation Of The Parctice Of Pancasila By People Gorontalo, Jurnal : Journal Of Humanity, III, (1), 1-11.

Sven Kosel, 2010. The History Of Islam In Bolaang Mongondow, North Sulawesi Rationalisation and derationalisation of religion, Journal : Indonesia and the Malay World Vol. 38. 43-64.

- Undang - Undang

Undang -Undang Dasar Negara Republik Indonesia 1945

Petaruran Daerah Provinsi Gorontalo Nomor 2 Tahun 2016 Tentang Penyelenggara Lembaga Adat.

- Internet

www.awdisulutnews.com.watungdisambut-masyarakat-bolaang. Di akses tanggal 7 mei 2017, 23 :15 Wita. 